\title{
Controle de Plantas Daninhas na Cultura da Soj a Através do herbicida ACETOCHLOR EM Sistemas de Semeadura Direta e Preparo Convencional ${ }^{1}$
}

\author{
Weed Control in Soybean Crop Using the Herbicide Acetochlor Under Direct Seeding and \\ Conventional System
}

FERRI, M.V.W. ${ }^{2}$ e VIDAL, R.A. ${ }^{3}$

\begin{abstract}
RESUMO - O manejo do solo altera a bioatividade dos herbicidas residuais e influi na persistência, na eficácia de controle das plantas daninhas e na fitotoxicidade para as culturas. Um experimento foi conduzido na Faculdade de Agronomia da Universidade Federal do Rio Grande do Sul, com objetivo de avaliar a eficácia de controle das plantas daninhas pelo herbicida acetochlor aplicado em solo Argissolo Vermelho sob semeadura direta e preparo convencional. O delineamento experimental foi o de blocos casualizados com quatro repetições em parcelas subsubdivididas. O acetochlor foi utilizado nas doses de 0, 1.680, 2.520, 3.360 e $4.200 \mathrm{~g} \mathrm{ha}^{-1}$. Foi avaliado o controle das plantas daninhas aos 15, 30 e 45 dias após aplicação do acetochlor (DAT). Foram avaliados também a injúria na cultura da soja aos 14, 21 e 28 DAT e a matéria seca das plantas daninhas aos 40 e 60 DAT. O herbicida acetochlor foi mais eficiente no controle das plantas daninhas no solo sob preparo convencional que sob semeadura direta. A produção de matéria seca dessas plantas foi menor no preparo convencional comparado à semeadura direta. Não ocorreu injúria à cultura da soja.
\end{abstract}

Palavras-chave: soja, adsorção, degradação biológica, lixiviação, persistência.

\begin{abstract}
Soil management affects herbicide bioactivity and changes persistence, weed control and crop selectivity. An experiment was carried out at the Federal University of Rio Grande do Sul - Brazil, to evaluate the efficacy of the herbicide acetochlor in controling weeds in a Paleudult soil under direct seeding and conventional system. The following treatments were tested: acetochlor at $0,1,680,2,520,3,360$ and 4,200 $\mathrm{g} \mathrm{ha}^{-1}$, applied under tillage and no-till systems. Assessments included crop injury at 14, 21 and 28 days after acetochlor aplication, weed dry matter at 40 and 60 days after herbicide aplication and weed control at 15, 30 and 45 days after acetochlor aplication. Acetochlor was more efficient under conventional than direct seeding system. Weed dry biomass was lower under conventional than direct seeding system. No soybean crop injury was observed.
\end{abstract}

Key words: soybean, adsorption, biological degradation, leaching, persistence.

\section{INTRODUÇÃO}

O manejo de solos afeta a atividade e a persistência dos herbicidas residuais devido aos seus efeitos sobre processos de transformação e/ou transferência das moléculas dos herbicidas no solo, como adsorção, lixiviação e degradação biológica. Esses processos regulam a concentração e a permanência das moléculas dos herbicidas na solução do solo e, dessa forma, a biodisponibilidade para controle das plantas daninhas e a fitotoxicidade para as culturas (Peter \& Weber, 1985; Mueller et al., 1999).

Recebido para publicação em 15/1/2002 e na forma revisada em 7/8/2002.

2 Eng.-Agr., Dr., Caixa Postal 138, 85550-000 Coronel Vivida-Pr, <mvwferri@ bol.com.br>. ${ }^{3}$ Eng.-Agr. Ph.D., Professor do Departamento de Plantas de Lavoura da Faculdade de Agronomia da UFRGS. Av. Bento Gonçalves, 7712, $91501-970$ Porto Alegre-RS. 
Por regular o equilíbrio entre o herbicida retido e o disponível na solução do solo, a adsorção afeta a maioria dos destinos desses compostos no solo, como a absorção pelas raízes das plantas daninhas, a degradação biológica, a volatilização e, em decorrência disso, a eficácia de controle de plantas daninhas. A intensidade da ação pode variar com o manejo do solo em função do efeito sobre o teor de matéria orgânica e umidade do solo (Stearman et al., 1989; Levanon et al., 1993).

A degradação biológica, por resultar na formação de metabólicos sem ação fitotóxica, reduz a atividade dos herbicidas aplicados no solo. Ela é favorecida pelo aumento da biomassa e atividade microbiana do solo. Dessa forma, as possiveis variações no teor de matéria orgânica, umidade e temperatura do solo, proporcionadas pelo manejo, normalmente afetam a atividade e a biomassa microbiana e podem reduzir a atividade e persistência dos herbicidas residuais, por favorecer as transformações biológicas desses compostos no solo (Walker, 1987; Reddy et al., 1995; Willian et al., 1997).

A lixiviação, por transportar as moléculas dos herbicidas para além do alcance das raízes das plantas daninhas, também reduz a atividade dos herbicidas aplicados no solo. Para um determinado solo, em suas diferentes formas de manejo, a lixiviação dos herbicidas pode aumentar com a estabilidade da estrutura. A estabilidade e a continuidade do sistema poroso, com possivel ocorrência de fluxo preferencial, podem favorecer a lixiviação desses compostos no solo, reduzindo assim a eficácia de controle das plantas daninhas (Isensee et al., 1990; Weed et al., 1995; Kalita et al., 1997).

A semeadura direta, comparada ao preparo convencional, devido à não-mobilização do solo e à presença da palha na superfície deste, eleva o teor superficial de matéria orgânica, mantém a estabilidade da estrutura e reduz as amplitudes de variação da umidade e temperatura do solo. Esses fatores podem incrementar a adsorção, a degradação biológica e a lixiviação e reduzir a atividade e a persistência das moléculas dos herbicidas no solo (Thomas \& Phillips, 1979; Levanon et al., 1993; Fuscaldo et al., 1999). Em razão disso, menor controle das plantas daninhas é esperado nesse sistema de preparo do solo. O objetivo deste trabalho foi avaliar o controle das plantas daninhas por meio do herbicida acetochlor em solo manejado sob semeadura direta e preparo convencional.

\section{MATERIAL E MÉTODOS}

O experimento foi conduzido na Estação Experimental Agronômica da Universidade Federal do Rio Grande do Sul (EEA/UFRGS), localizada no município de Eldorado do Sul, região fisiográfica da Depressão Central do RS. O solo utilizado pertence à unidade de mapeamento São Jerônimo, sendo classificado como Argissolo Vermelho distrófico típico. O manejo adotado foi semeadura direta (seis anos consecutivos) e preparo convencional (aração e gradagem anual). A área de semeadura direta consistiu da semeadura de aveia (Avena strigosa) em junho de 1999, para obtenção de cobertura do solo com palha. Nessa área, a vegetação existente sobre a superfície do solo foi controlada com $1.080 \mathrm{~g} \mathrm{ha}^{-1}$ de glyphosate dois dias antes da aplicação dos tratamentos. As principais plantas daninhas presentes na área experimental foram Digitaria horizontalis (milhã), Bidens pilosa (picão-preto), Sida rhombifolia (guanxuma) e Brachiaria plantaginea (papuã).

O herbicida acetochlor, 2-cloro-N(etoximetil)-N-(2-etil-6-metil-fenil) acetamida, pertence ao grupo das acetanilidas. Ele foi aplicado com pulverizador costal pressurizado a $\mathrm{CO}_{2}$, com pressão de $200 \mathrm{kPa}$, bicos tipo leque 8002 , distanciados em $0,50 \mathrm{~m}$ na barra de 1,5 m e com volume de calda de $220 \mathrm{~L} \mathrm{ha}^{-1}$.

O delineamento experimental utilizado foi o de blocos casualizados com quatro repetições, sendo os tratamentos distribuídos em parcelas subsubdivididas. As unidades experimentais mediram $2 \times 4 \mathrm{~m}$. Nas parcelas principais encontravam-se o preparo do solo: semeadura direta e preparo convencional; nas subparcelas, as doses do herbicida acetochlor: 0, 1.680, 2.520, 3.360 e $4.200 \mathrm{~g} \mathrm{ha}^{-1}$; e nas subsubparcelas, as épocas de avaliação de controle das plantas daninhas: 15, 30 e 45 dias após aplicação do acetochlor (DAT). Além disso, foram avaliadas a injúria do herbicida acetochlor à cultura da soja aos 14, 21 e 28 DAT e a matéria seca das plantas daninhas aos 40 e 60 DAT, por meio de coleta de área de $0,25 \mathrm{~m}^{2}$. Após a coleta, as plantas daninhas foram secas em estufa a $60^{\circ} \mathrm{C}$, até peso constante. 
O controle das plantas daninhas pelo herbicida acetochlor foi avaliado visualmente, atribuindo-se notas de controle que variaram de 0 a 100, sendo 0 para ausência de controle das plantas e 100 para controle total das plantas. $\mathrm{Na}$ avaliação da injúria foram atribuídas notas relativas aos sintomas do herbicida na parte aérea das plantas de soja, que variaram de 0 a 100, sendo 0 para injúria nula e 100 para destruição total das plantas de soja.

Foi realizada caracterização físico-química do solo através da avaliação de densidade, macroporosidade, microporosidade e porosidade total do solo, condutividade hidráulica saturada, por metodologias descritas no Manual de Métodos de Análise de solo (Empresa...EMBRAPA, 1979), e carbono orgânico total do solo, conforme metodologia descrita em Tedesco et al. (1995).

$\mathrm{Na}$ análise estatística, os dados relativos à porcentagem de controle e injúria à cultura da soja sofreram transformação arco seno $\sqrt{x / 100}$ antes de serem submetidos à análise de variância. Os efeitos quantitativos das doses do herbicida acetochlor foram avaliados por análise de regressão.

\section{RESULTADOS E DISCUSSÃO}

Os dados da Tabela 1 mostram diferenças entre o solo sob semeadura direta e aquele sob preparo convencional para todas as variáveis estudadas. Foi observada maior densidade e microporosidade na profundidade de $0-5 \mathrm{~cm}$ na semeadura direta. Observou-se, também, neste sistema de preparo, menor densidade do solo na profundidade de $15-20 \mathrm{~cm}$. A porosidade total e a macroporosidade foram maiores no solo com preparo convencional na profundidade de $0-5 \mathrm{~cm}$ e na semeadura direta na profundidade de $15-20 \mathrm{~cm}$. Além disso, o carbono orgânico total, na profundidade de $0-10 \mathrm{~cm}$, foi maior no solo sob semeadura direta. A condutividade hidráulica saturada foi maior na profundidade de $0-10 \mathrm{~cm}$ no solo com preparo convencional e de $10-20 \mathrm{~cm}$ na semeadura direta (Tabela 1). O preparo do solo, por ter elevado a porosidade total e a macroporosidade na profundidade de $0-5 \mathrm{~cm}$, pode ter favorecido a condutividade hidráulica saturada na profundidade de $0-10 \mathrm{~cm}$. A ausência de preparo do solo e a conseqüente manutenção da estabilidade da estrutura podem ter favorecido a condutividade hidráulica saturada na profundidade de $10-20 \mathrm{~cm}$, na semeadura direta.

A presença de palha na superfície do solo pode ter contribuído para elevar o teor superficial de carbono orgânico no solo sem preparo. Estudos envolvendo efeito do preparo do solo sobre características físicas e químicas, em profundidade no solo, normalmente produzem resultados conflitantes, dependendo da textura, do sistema e tempo de preparo e da profundidade do solo avaliada. A ausência de preparo normalmente proporciona aumento da densidade e do teor de carbono orgânico nas camadas superficiais do solo. Já o preparo do solo proporciona aumento da macroporosidade e redução da densidade do solo (Blewins et al., 1983; Dick, 1983; Shipitalo et al., 2000).

Tabela 1 - Densidade, macro, micro e porosidade total, condutividade hidráulica saturada e carbono orgânico total, em diferentes profundidades de coleta, em solo sob semeadura direta e preparo convencional. EEA/UFRGS, Eldorado do SulRS, 1999/2000

\begin{tabular}{|c|c|c|c|c|c|c|c|c|c|c|c|c|}
\hline \multirow{3}{*}{$\begin{array}{l}\text { Profundidade } \\
\text { do solo } \\
\text { (cm) }\end{array}$} & \multicolumn{2}{|c|}{$\begin{array}{c}\text { Densidade do } \\
\text { solo } \\
\left(\mathrm{g} \mathrm{cm}^{-3}\right)\end{array}$} & \multicolumn{2}{|c|}{$\begin{array}{l}\text { Macroporosidade } \\
\qquad\left(\mathrm{m}^{3} \mathrm{~m}^{-3}\right)\end{array}$} & \multicolumn{2}{|c|}{$\begin{array}{l}\text { Microporosidade } \\
\qquad\left(\mathrm{m}^{3} \mathrm{~m}^{-3}\right)\end{array}$} & \multicolumn{2}{|c|}{$\begin{array}{l}\text { Porosidade } \\
\text { total } \\
\left(\mathrm{m}^{3} \mathrm{~m}^{-3}\right)\end{array}$} & \multicolumn{2}{|c|}{$\begin{array}{l}\text { Condutividade } \\
\text { hidráulica saturada } \\
\left(\mathrm{cm} \mathrm{h}^{-1}\right)^{4 /}\end{array}$} & \multicolumn{2}{|c|}{$\begin{array}{c}\text { Carbono orgânico } \\
\text { total } \\
\left(\mathrm{mg} \mathrm{g}^{-1}\right)\end{array}$} \\
\hline & \multicolumn{12}{|c|}{ Sistemas de preparo de solo } \\
\hline & $\mathrm{SD}^{1 /}$ & $\mathrm{PC}^{2 \prime}$ & SD & $\mathrm{PC}$ & SD & $\mathrm{PC}$ & SD & $\mathrm{PC}$ & SD & PC & SD & $\mathrm{PC}$ \\
\hline $0-5$ & $1,64 \mathrm{Ca}^{3 / 1}$ & $1,34 \mathrm{Db}$ & $0,193 \mathrm{Ab}$ & $0,279 \mathrm{Aa}$ & $0,170 \mathrm{BCa}$ & $0,138 \mathrm{Db}$ & $0,363 \mathrm{ABb}$ & $0,415 \mathrm{Aa}$ & & & $15,1 \mathrm{Aa}$ & $12,8 \mathrm{Ab}$ \\
\hline $5-10$ & $1,66 \mathrm{BCa}$ & $1,59 \mathrm{Ca}$ & $0,217 \mathrm{Aa}$ & $0,204 \mathrm{Ba}$ & $0,164 \mathrm{Ca}$ & $0,159 \mathrm{Ca}$ & $0,381 \mathrm{Aa}$ & $0,363 \mathrm{Ba}$ & $15,8 \mathrm{Ab}$ & $24,1 \mathrm{Aa}$ & $11,8 \mathrm{Ba}$ & $10,4 \mathrm{Bb}$ \\
\hline $10-15$ & $1,72 \mathrm{ABa}$ & $1,71 \mathrm{Ba}$ & $0,177 \mathrm{BCa}$ & $0,183 \mathrm{Ca}$ & $0,182 \mathrm{Aa}$ & $0,171 \mathrm{Ba}$ & $0,359 \mathrm{Ba}$ & $0,354 \mathrm{Ba}$ & & & $8,8 \mathrm{Cb}$ & $12,2 \mathrm{Ba}$ \\
\hline $15-20$ & $1,76 \mathrm{Ab}$ & $1,82 \mathrm{Aa}$ & $0,159 \mathrm{Ca}$ & $0,13 \mathrm{Db}$ & $0,178 \mathrm{ABa}$ & $0,181 \mathrm{Aa}$ & $0,337 \mathrm{Ca}$ & $0,314 \mathrm{Cb}$ & $11,1 \mathrm{Ba}$ & $5,1 \mathrm{Bb}$ & $8,5 \mathrm{Ca}$ & $8,6 \mathrm{Ca}$ \\
\hline $\mathrm{CV}^{5 /}(\%)$ & \multicolumn{2}{|c|}{1,9} & \multicolumn{2}{|c|}{5,0} & \multicolumn{2}{|c|}{2,1} & \multicolumn{2}{|c|}{2,5} & \multicolumn{2}{|c|}{\begin{tabular}{|c|}
18,0 \\
\end{tabular}} & \multicolumn{2}{|c|}{4,3} \\
\hline
\end{tabular}

${ }^{1 /} \mathrm{SD}=$ semeadura direta; ${ }^{2 /} \mathrm{PC}=$ preparo convencional; ${ }^{3 /}$ Médias seguidas pela mesma letra maiúscula nas colunas e minúscula nas linhas não diferem pelo teste de Tukey (P > 0,05); ${ }^{4 /}$ Condutividade hidráulica saturada, profundidades de 0-10 e 10-20 cm; e ${ }^{5 /}$ Coeficiente de variação. 
O controle das plantas daninhas variou entre os sistemas de preparo do solo, as doses do herbicida acetochlor e as épocas de avaliações. O controle foi menor no solo sob semeadura direta, comparada ao preparo convencional, nas avaliações realizadas aos 30 e 50 DAT, em todas as doses do herbicida acetochlor utilizadas (Figuras 1 e 2). Considerando $85 \%$ de controle das plantas daninhas como o mínimo necessário para prevenir danos às culturas por competição, a maior dose do herbicida acetochlor utilizada controlou as plantas daninhas num período inferior a 30 e 50 DAT nos solos sob semeadura direta e preparo convencional, respectivamente (Figuras 1 e 2). Além disso, considerando que o período total de prevenção de interferência termina aproximadamente aos 50 dias da emergência para a cultura da soja (Durigan et al., 1983; Fleck et al., 1989), nenhuma das doses do acetochlor utilizadas, tanto na semeadura direta quanto no preparo convencional, proporcionou período satisfatório de controle das plantas daninhas.
Essa situação se agrava na semeadura direta, em que o período de controle adequado foi inferior a 30 dias da emergência dessa cultura (Figura 1). Especula-se que o incremento no teor superficial de matéria orgânica e a manutenção da estabilidade de estrutura do solo (Tabela 1) podem ter favorecido a adsorção, a degradação biológica e a lixiviação do acetochlor no solo sob semeadura direta e conduzido, dessa forma, ao baixo controle das plantas daninhas observado neste trabalho.

A matéria seca produzida pelas plantas daninhas variou entre os sistemas de preparo de solo e as doses de acetochlor utilizadas (Figura 3). Comparada à semeadura direta, a produção de matéria seca foi menor no solo sob preparo convencional em ambas as épocas de avaliação. A maior eficácia de controle das plantas daninhas observada neste sistema de preparo de solo (Figura 2) conduziu à menor produção de matéria seca observada.

Para variável injúria de plantas da soja ocorreu interação entre doses do herbicida

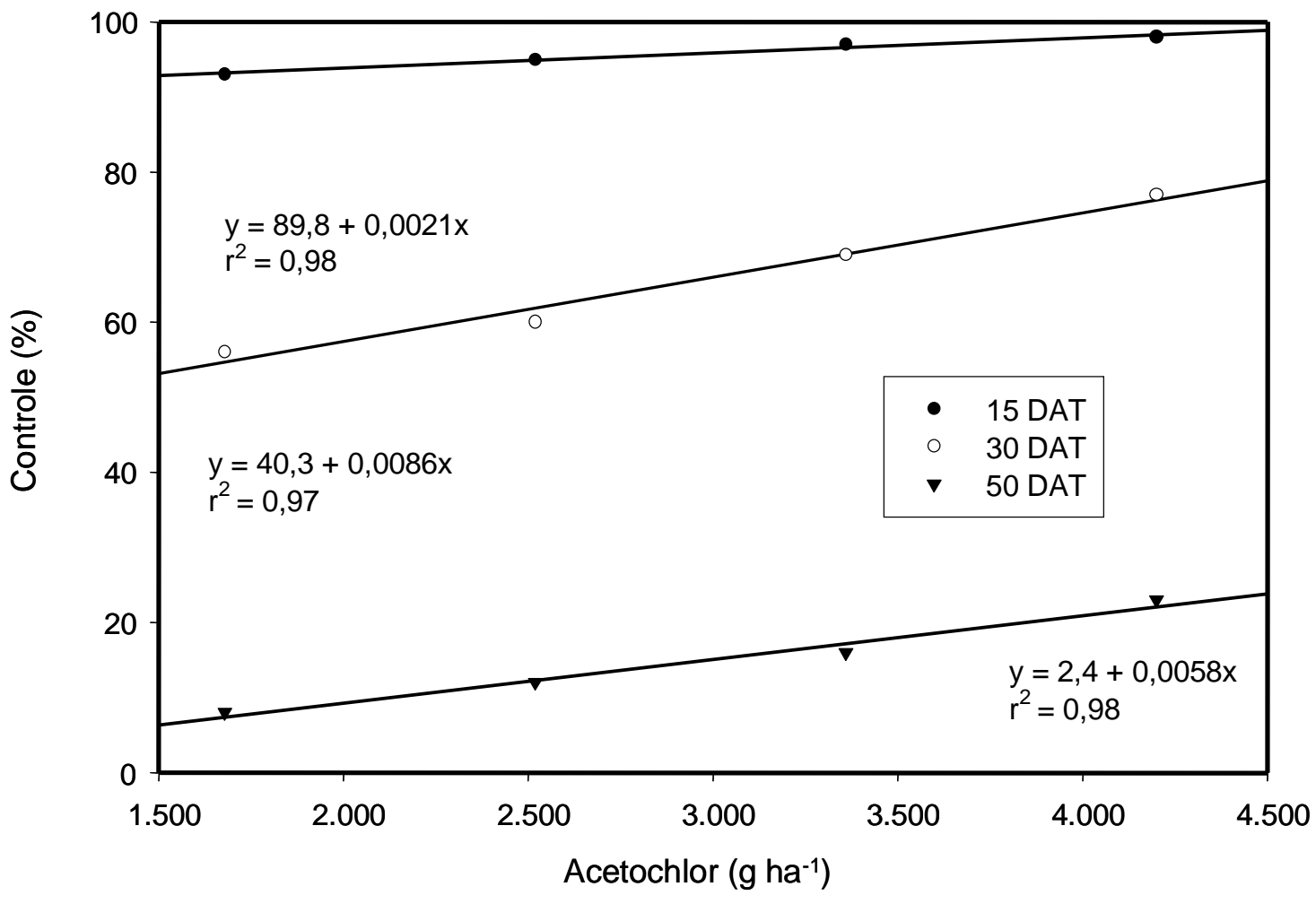

Figura 1 - Controle de plantas daninhas pelo acetochlor em diferentes épocas de avaliação no sistema de semeadura direta. EEA/ UFRGS, Eldorado do Sul-RS, 1999/2000. 
acetochlor e época de avaliação (Figura 4). A injúria na soja foi maior aos 14 que aos 21 DAT e desapareceu completamente aos 28 DAT, em todas as doses utilizadas. Os sintomas de toxicidade na parte aérea das plantas de soja não excederam a $10 \%$, sugerindo que o acetochlor não causa danos significativos à cultura da soja mesmo na dose de $4.200 \mathrm{~g} \mathrm{ha}^{-1}$.

Os resultados observados neste trabalho demonstraram significativa variação de eficácia e atividade residual para controle das plantas daninhas pelo acetochlor entre os solos submetidos à semeadura direta e ao preparo convencional. A atividade e a persistência dos herbicidas residuais podem variar entre os sistemas de preparo do solo. Alterações nos níveis de adsorção, degradação e/ou transformação biológica e lixiviação dos herbicidas, induzidas pelas variações nas propriedades físicas e químicas do solo, decorrentes do manejo, conduzem a variações de atividade dos herbicidas aplicados no solo (Peter \& Weber, 1985; Willian et al., 1997; Mueller et al., 1999). O maior teor superficial $(0-5 \mathrm{~cm})$ de matéria orgânica, observado no solo sob semeadura direta (Tabela 1), pode ter incrementado a adsorção do herbicida acetochlor e reduzido sua atividade para controle das plantas daninhas. A adsorção regula a concentração das moléculas dos herbicidas na solução do solo e, com isso, a absorção pelas raízes dessas plantas (Peter \& Weber, 1985; Levanon et al., 1993), sendo esta uma possível explicação para o menor controle observado no solo sob semeadura direta.

Além dos efeitos sobre a adsorção de herbicidas, a matéria orgânica incrementa a biomassa e atividade microbiana do solo e, assim, as transformações biológicas sofridas pelas moléculas dos herbicidas presentes no solo (Lavy et al., 1996; Walker, 1987; Yen et al., 1994). Dessa forma, o menor controle das plantas daninhas proporcionado pelo herbicida acetochlor no solo sob semeadura direta pode também ser decorrente do aumento da degradação e/ou transformação biológica desse herbicida neste solo.

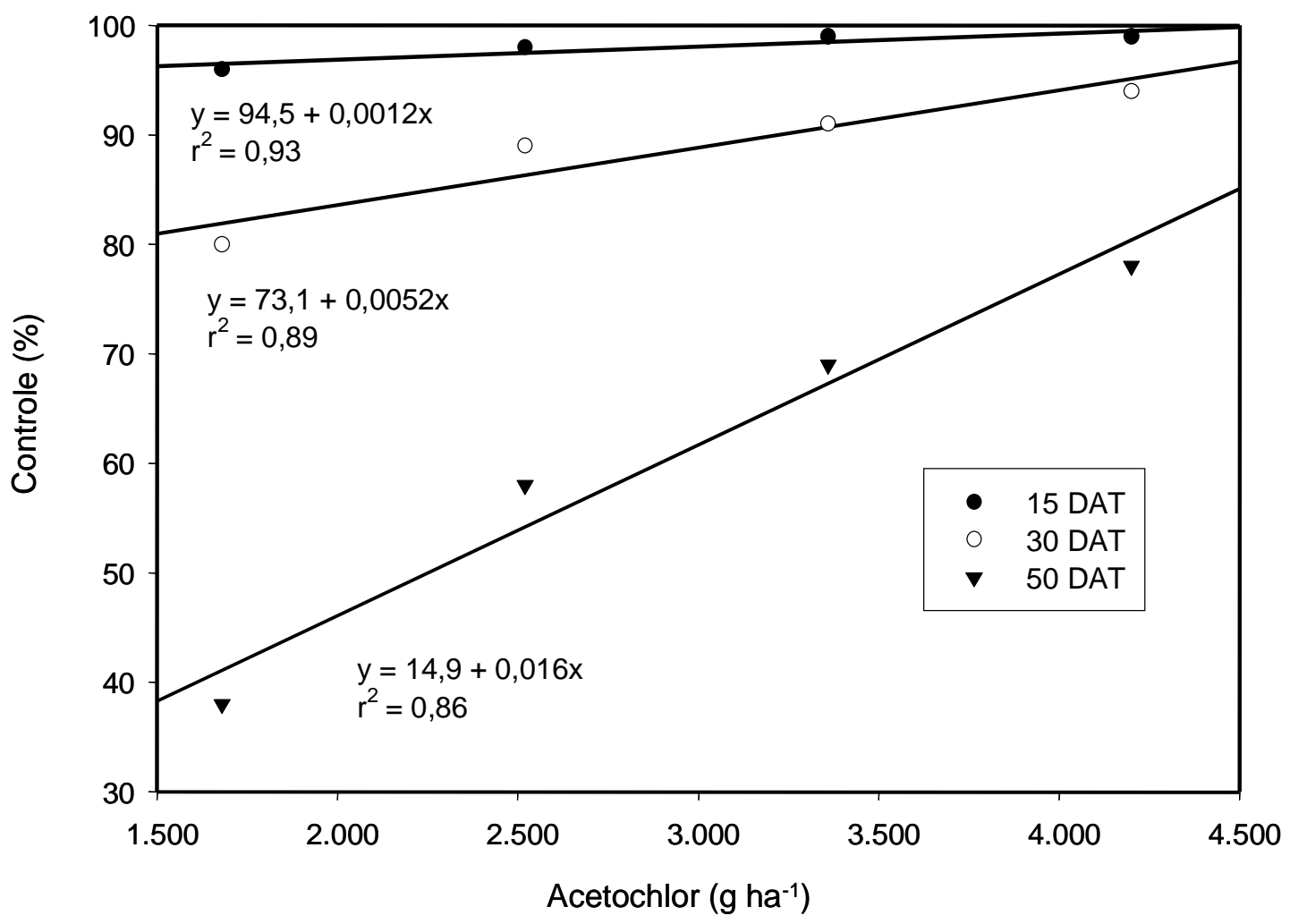

Figura 2 - Controle de plantas daninhas pelo acetochlor em diferentes épocas de avaliação no sistema de semeadura convencional. EEA/UFRGS, Eldorado do Sul-RS, 1999/2000. 


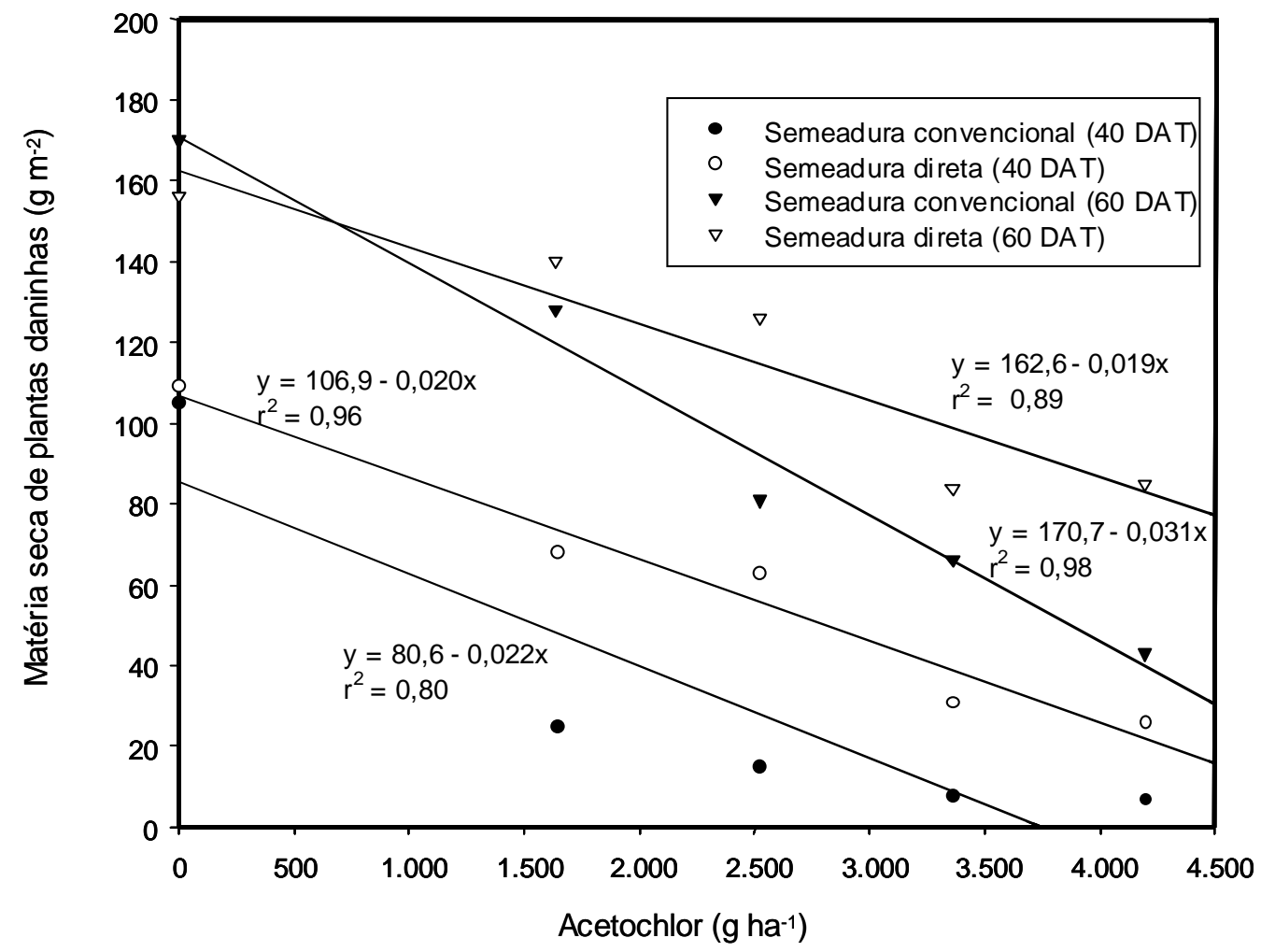

Figura 3 - Matéria seca de plantas daninhas em função da época de avaliação, das doses do herbicida acetochlor e dos sistemas de preparo de solo. EEA/UFRGS, Eldorado do Sul-RS, 1999/2000.

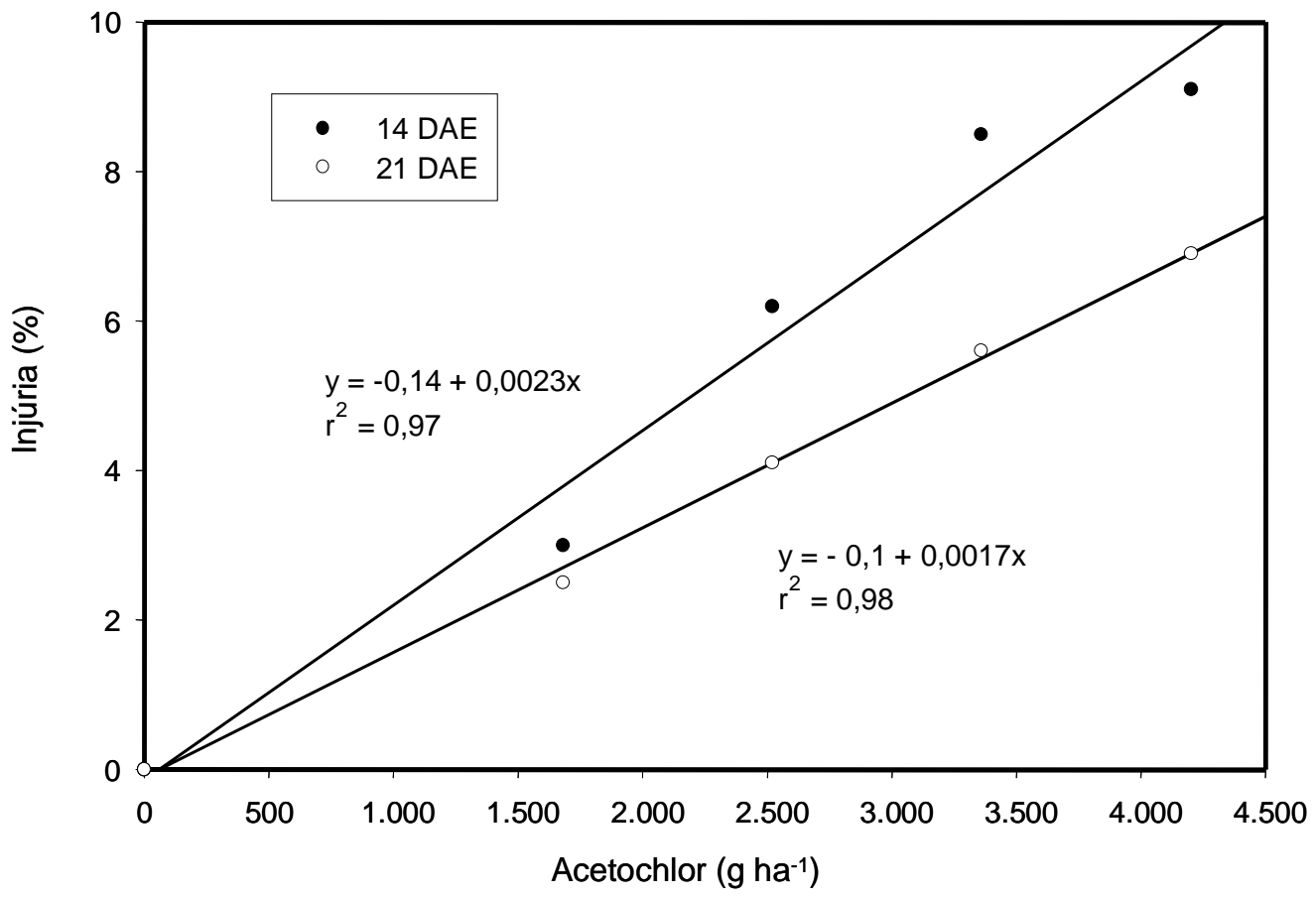

Figura 4 - Injúria em plantas de soja em função de doses do herbicida acetochlor e da época após a emergência da cultura. EEA/ UFRGS, Eldorado do Sul-RS, 1999/2000. 
Além do maior teor superficial de matéria orgânica, também se observou maior condutividade hidráulica saturada no solo submetido à semeadura direta (Tabela 1). A condutividade hidráulica saturada pode ser considerada como parâmetro indicativo do tamanho, da estabilidade e da continuidade do sistema poroso do solo, que, por sua vez, determinam as taxas de movimento de água no solo (Blewins et al., 1983; Crawford, 1994). Conseqüentemente, sistemas de manejo que privilegiem a manutenção da estabilidade e continuidade do sistema poroso do solo, como é o caso da semeadura direta, podem aumentar a lixiviação de herbicidas residuais (Isensee et al., 1990). Assim, além dos possíveis efeitos da adsorção e degradação biológica, o menor controle das plantas daninhas observado no solo sob semeadura direta pode ter sido decorrente da lixiviação das moléculas do herbicida acetochlor para além do alcance das raízes dessas plantas.

Os resultados observados neste trabalho permitem especular que as variações de controle das plantas daninhas observadas entre os solos sob semeadura direta e preparo convencional possam ser decorrentes da redução da atividade e persistência do acetochlor, proporcionadas pela ação simultânea de processos de transformação e/ou transferência das moléculas dos herbicidas no solo, como adsorção, degradação biológica e lixiviação. Em razão dos resultados obtidos, conclui-se que o herbicida acetochlor foi mais eficiente no controle das plantas daninhas no solo sob preparo convencional que naquele sob semeadura direta.

\section{LITERATURA CITADA}

BLEWINS, R. L. et al. Influence of conservation tillage on soil properties. J. Soil Water Conser., v. 38, n. 1, p. 301305, 1983.

CRAWFORD, J. W. The relationship between structure and the hydraulic conductivity of soil. Europ. J. Soil Sci., v. 45, n. 2, p. 493-502, 1994.

DICK, W. A. Organic carbon, nitrogen, and phosphorus concentrations and $\mathrm{pH}$ in soil profiles as affected by tillage intensity. Soil Sci. Soc. Am. J., v. 47, n. 1, p. 102-107, 1983.

DURIGAN, J. C. et al. Períodos de matocompetição na cultura da soja (Glycine max (L.) Merrill), cultivares Santa Rosa e IAC-2. I. - Efeitos sobre os parâmetros de produção. Planta Daninha, v. 2, n. 1, p. 86-100, 1983.
EMPRESA BRASILEIRA DE PESQUISA AGROPECUÁRIA - EMBRAPA. Manual de Métodos de Análise do Solo. Rio de Janeiro: EMBRAPA-SNLCS, 1979. $1010 \mathrm{p}$.

FLECK, N. G.; MENGARDA, I. P.; PINTO, J. J. O. Interferência de plantas daninhas na cultura de girassol. Competição no tempo. Pesq. Agropec. Bras., v. 24, n. 9 , p. 1139-1147, 1989.

FUSCALDO, F.; BEDMAR, F.; MONTERUBBIANESI, G. Persistence of atrazine, metribuzin and simazine herbicides in two soils. Pesq. Agropec. Bras., v. 34, n. 11, p. 20372044, 1999.

ISENSEE, A. R.; NASH, R. G.; HELLING, C. S. Effects of conventional vs. no tillage on pesticide leaching to shallow groundwater. J. Environ. Qual., v. 19, n. 2, p. 434-440, 1990.

KALITA, P. K. et al. Groundwater residues of atrazine and alachlor under water-table management practices. Trans. Am. Soil Agric. Engin., v. 40, n. 3, p. 605-614, 1997.

LAVY, T. L. et al. Long-term in situ leaching and degradation of six herbicides aged in subsoils. J. Environ. Qual., v. 25, n. 5, p. 1268-1279, 1996.

LEVANON, D. et al. Mobility of agrocemicals through soil from two tillage systems. J. Environ. Qual., v. 22, n. 1, p. 155-161, 1993.

MUELLER, T. C.; SHAW, D. R.; WITT, W. W. Relative dissipation of acetochlor, alachlor, metolachlor, and SAN 582 from three surface soils. Weed Sci., v. 13, n. 1, p. 341346, 1999.

PETER, C. J.; WEBER, B. J. Adsorption, mobility and efficacy of alachlor and acetochlor as influenced by soil properties. Weed Sci., v. 33, n. 3, p. 874-881, 1985.

REDDY, K. N.; ZABLOTOWICZ, R. M.; LOCKE, M. A. Chlorimuron adsorption, desorption, and degradation in soils from conventional tillage and no-tillage systems. J. Environ. Qual., v. 24, p. 760-767, 1995.

SHIPITALO, M. J.; DICK, W. A.; EDWARDS, W. M. Conservation tillage and macropore factors that affect water movement and the fate of chemicals. Soil Till. Res., v. 53, n. 3-4, p. $167-183,2000$.

STEARMAN, G. K. et al. Herbicides reativity of soil organic matter fractions in no-tilled and tilled cotton. J. Soil Sci. Am. Soc., v. 53, n. 6, p. 1690-1694, 1989.

Planta Daninha, Viçosa-MG, v.20, n.2, p.283-290, 2002 
TEDESCO, M. et al. Análises de solo, plantas e outros materiais. Porto Alegre: Universidade Federal do Rio

Grande do Sul, 1995. 173 p. (Boletim Técnico de Solos, 5).

THOMAS, G. W.; PHILLIPS, R. E. Consequences of water movement in macropores. J. Environ. Qual., v. 8, n. 2, p. $149-152,1979$.

WALKER, A. Herbicide persistence in soil. Rev. Weed Sci., v. 3, p. 1-17, 1987.
WEED, D. A. J. et al. Dissipation and distribution of herbicides in the soil profile. J. Environ. Qual., v. 24, n. 1, p. 68-79, 1995.

WILLIAN, T. W. et al. Adsorption, dissipation and movement of fluometuron in three Southeastern United States soils. Weed Sci., v. 45, n. 1, p. 183-189, 1997.

YEN, P. Y.; KOSKINEN, W. C.; SCHEIZER, E. E. Dissipation of alachlor in four soils influenced by degradation and sorption processes. Weed Sci., v. 42, n. 1, p. 233-240, 1994. 